\title{
Lack of Association of White Matter Lesions with Ipsilateral Carotid Artery Stenosis
}

\author{
Gillian M. Potter ${ }^{a, b}$ Fergus N. Doubal ${ }^{a}$ Caroline A. Jackson $^{a}$ \\ Cathie L.M. Sudlow ${ }^{a}$ Martin S. Dennis ${ }^{a}$ Joanna M. Wardlawa, ${ }^{a}$ \\ aDivision of Clinical Neurosciences, Brain Research Imaging Centre, University of Edinburgh, Western General \\ Hospital, and bSINAPSE Collaboration, SFC Brain Research Imaging Centre, Western General Hospital, \\ Edinburgh, UK
}

\author{
Key Words \\ Leukoaraiosis $\cdot$ White matter lesions $\cdot$ Aetiology $\cdot$ Carotid \\ stenosis $\cdot$ Atheroma $\cdot$ Thromboembolism $\cdot$ Magnetic \\ resonance imaging
}

\begin{abstract}
Background: White matter lesions (WML) are commonly seen on brain MRI and are generally considered a marker of tissue damage from cerebral small vessel disease. WML are associated with increasing age and vascular risk factors, but their precise cause is unknown. A role for carotid artery atherothromboemboli has been suggested. If this is the case, more WML would be expected ipsilateral to increasing degrees of carotid stenosis. Methods: We recruited patients with ischaemic stroke from two large, separate prospective stroke studies, assessed with brain MRI and carotid Doppler ultrasound. We scored hemispheric WML visually in periventricular and deep locations. We assessed the association between carotid stenosis asymmetry and WML asymmetry, and vice versa. Further, we assessed the association between carotid stenosis and ipsilateral WML, before and after adjusting for vascular risk factors, and tested associations between ipsilateral and contralateral stenoses and WML. Results: We recruited 247 (Study 1) and 253 (Study 2) patients. In Study 1
\end{abstract}

and Study 2, 36 (15\%) and 29 (11\%) patients had $\geq 50 \%$ carotid stenosis, and $27(11 \%)$ and $15(6 \%)$ had $\geq 70 \%$ stenosis, respectively. Carotid stenosis was asymmetric in $28(11 \%)$ and $26(10 \%)$ patients and WML were asymmetric in $22(9 \%)$ and 11 (4\%) patients in Study 1 and Study 2, respectively. We found no association between carotid stenosis and ipsilateral WML score, before or after adjusting for vascular risk factors or sidedness, but WML were strongly associated with increasing age $(p<0.001)$. Conclusion: In two large cohorts of ischaemic stroke patients, we found no association between carotid stenosis and ipsi- or contralateral WML. There is now substantial evidence that atherothromboemboli are unlikely to cause most WML or other forms of cerebral small vessel lesions. Future studies should focus on determining what causes the intrinsic small vessel pathological changes that appear to underlie most WML.

Copyright $\odot 2012$ S. Karger AG, Basel

\section{Introduction}

White matter lesions (WML), also termed 'leukoaraiosis' [1], are commonly seen on brain magnetic resonance imaging (MRI) in older people and are associated with symptoms common in old age, including impaired

\begin{tabular}{ll}
\hline KARGER & $\begin{array}{l}\text { ○ 2012 S. Karger AG, Basel } \\
1015-9770 / 12 / 0334-0378 \$ 38.00 / 0 \quad \text { Karger }\end{array}$ \\
E-Mail karger@karger.ch & $\begin{array}{l}\text { Thisis an Open Access article licensed under the terms of the } \\
\text { Creative Commons Attribution-NonCommercial 3.0 Un- } \\
\text { ported license (CC BY-NC) (www.karger.com/OA-license), } \\
\text { applicable to the online version of the article only. Distribu- } \\
\text { tion permitted for non-commercial purposes only. }\end{array}$
\end{tabular}

Prof. J.M. Wardlaw

Division of Clinical Neurosciences, Western General Hospital

Bramwell Dott Building, Crewe Road

Edinburgh EH4 2XU (UK)

Tel. +44 131537 2943, E-Mail joanna.wardlaw@ed.ac.uk 
balance and gait, depression, cognitive impairment and dementia $[2,3]$, as well as with worse functional outcome after stroke [4]. Their precise cause is unknown [5], but as well as being associated with increasing age, they are associated with hypertension, diabetes, other vascular risk factors [6] and markers of carotid atheroma such as intima media thickening and carotid plaques [7]. If WML are caused by emboli (either from carotid atheroma, cardiac or other sources), then they should be greater in the cerebral hemisphere ipsilateral to a more severe carotid stenosis. Here, we assessed the association between carotid stenosis and ipsilateral WML.

\section{Methods}

We recruited patients who underwent brain MRI from two prospective studies: a hospital-based stroke register of consecutive patients with stroke or transient ischaemic attack presenting to a large academic teaching hospital between 2002 and 2005 (Study 1), and a study of patients with mild stroke presenting to the same hospital between 2005 and 2007 (Study 2). The recruitment periods did not overlap. Full details have been published previously $[8,9]$, together with MRI findings. The patients were assessed by experienced stroke physicians, who recorded baseline demographics, National Institutes of Health Stroke Scale (NIHSS) scores, vascular risk factors and other details $[8,9]$. Hypertension and diabetes mellitus were defined as previous diagnosis of, or on current treatment for, hypertension or diabetes, respectively. $\mathrm{Pa}$ tients were assigned an Oxfordshire Community Stroke Project (OCSP) stroke subtype [10], modified following radiological assessment to a 'final' stroke subtype. Study 1 included all OCSP ischaemic stroke subtypes, and Study 2 included lacunar, partial anterior and posterior circulation stroke syndromes only. We performed routine stroke investigations on all patients (details published previously $[8,9])$. Written informed consent was obtained from all patients, and both studies were approved by the local Research Ethics Committee.

We performed carotid Doppler ultrasound, blinded to other imaging results and to most clinical features except that the patient had had stroke-like symptoms, using a 7.5-MHz linear transducer and optimized colour Doppler mode. Stenosis was defined according to the North American Symptomatic Carotid Endarterectomy Trial (NASCET) criteria [11] using peak systolic velocity measurements as previously described [12-14]. The carotid artery contralateral to the side of the body affected by the stroke symptoms was defined as symptomatic.

The patients underwent brain MRI (GE Signa 1.5T scanner), including axial diffusion- and $\mathrm{T}_{2}$-weighted imaging (T2WI), fluid-attenuated inversion recovery (FLAIR), gradient echo and $\mathrm{T}_{1^{-}}$ weighted sagittal imaging $[8,9]$. All patients in Study 2 and about a quarter of patients in Study 1 had MRI.

We defined recent infarcts as hyperintense on diffusionweighted imaging, hypointense on the apparent diffusion coefficient map and either normal or hyperintense to the brain on FLAIR/T2WI. A neuroradiologist, aware of the side of acute stroke symptoms but blinded to other clinical and imaging data,

Lack of Association between Carotid

Stenosis and WML assessed the brain MRI scans at non-overlapping time points (G.M.P. Study 1, J.M.W. Study 2). The reader of Study 1 was unaware of the hypothesis being tested and blinded to data from Study 2. Hemispheric WML were rated using FLAIR and/or T2WI using the Fazekas scale [15], scoring 0-3 (for deep and periventricular $\mathrm{WML}$, where $0=$ none and $3=$ severe). For total hemispheric WML, we added scores in the deep and periventricular regions and obtained the average. Both neuroradiologists had undergone extensive WML rating training and rated a validated test set of $20 \mathrm{MRI}$ scans for WML to standardise performance.

\section{Statistical Analysis}

We examined both studies to identify if the data were sufficiently comparable before combining them for some of the analyses. Keeping the studies separate, we first sought evidence of WML score asymmetry between the cerebral hemispheres in individual patients and compared it with carotid stenosis asymmetry. We defined stenosis asymmetry as one carotid artery measuring $<50 \%$, and the contralateral artery measuring $\geq 50 \%$ stenosis, and WML asymmetry as a one-point difference in the Fazekas score between hemispheres, for both periventricular and deep locations. We combined the studies and assessed asymmetry of stenosis/WML and the association between carotid stenosis and ipsilateral WML before and after adjusting for potential confounders (age, diabetes and hypertension), using binary logistic regression. We analysed WML/carotid stenosis associations by comparing symptomatic versus asymptomatic, and left versus right, hemispheres within each patient. In the logistic regression model, we dichotomised the scores for overall (periventricular plus deep) WML as mild (0, 0.5, 1.0) versus severe $(1.5,2.0,2.5$, 3.0). For the analyses, we used Minitab Statistical Software (Version 15, Minitab Inc., State College, Pa., USA).

\section{Results}

Study 1 included 247 (mean age $69 \pm 13$ years) and Study 2 included 253 (mean age $68 \pm 11$ years) acute stroke patients. The proportions of patients with vascular risk factors and the distribution of stroke severities were similar in both studies (table 1). There were 80 (32\%) patients in Study 1 and 129 (51\%) in Study 2 with a final diagnosis (taking account of clinical and imaging features) of lacunar stroke. The median periventricular and deep WML scores were 1 (IQR 1-2) in both studies. Carotid stenosis on at least one side of $\geq 50 \%$ was present in 36 (15\%) and of $\geq 70 \%$ (including occluded) in 27 (11\%) patients in Study 1, and 29 (11\%) and 15 (6\%) patients in Study 2 , respectively. The range of stenosis in both studies ranged from 0 to $100 \%$ (occluded).

Carotid stenosis was asymmetric in 28 (11\%) and 26 (10\%) patients in Study 1 and Study 2, respectively (table 2); across both studies, only 4 patients had asymmetric WML (WML score higher distal to the stenosed side 
Table 1. Baseline clinical and imaging characteristics showing no significant differences between acute ischaemic stroke patients in Study 1 and Study 2

\begin{tabular}{lcc}
\hline & $\begin{array}{c}\text { Study 1 } \\
(\mathrm{n}=247)\end{array}$ & $\begin{array}{c}\text { Study 2 } \\
(\mathrm{n}=253)\end{array}$ \\
\hline Demographics & & \\
$\quad$ Mean age \pm SD, years & $69 \pm 13$ & $68 \pm 11$ \\
Males & $133(54)$ & $165(65)$ \\
Previous stroke & $45(18)$ & $23(9)$ \\
Diabetes & $25(10)$ & $36(14)$ \\
Hypertension & $131(53)$ & $154(61)$ \\
Previous AF & $40(16)$ & $22(9)$ \\
Lacunar stroke subtype & $80(32)$ & $129(51)$ \\
Median NIHSS score (IQR) & $1(0-3)^{\mathrm{a}}$ & $2(2-3)$ \\
Imaging parameters & & \\
Median PVL $(\mathrm{IQR})$ & $1(1-2)$ & $1(1-2)$ \\
Median DWML & $1(1-2)$ & $1(1-2)$ \\
\hline
\end{tabular}

Values are numbers of patients with percentages in parentheses unless otherwise indicated.

$\mathrm{PVL}=$ Periventricular white matter lesions; DWML = deep white matter lesions; AF = atrial fibrillation.

${ }^{\mathrm{a}} \mathrm{n}=230 .{ }^{\mathrm{b}} \mathrm{PVL}$ and DWML rated according to the Fazekas scale.

Table 2. Association between carotid stenosis asymmetry and WML asymmetry

$\begin{array}{lll}\text { WML } & \text { WML } & \text { Total } \\ \text { asymmetric } & \text { symmetric } & \end{array}$

\begin{tabular}{lrrr}
\hline Study 1 & & & \\
$\quad$ Stenosis asymmetric & $2^{\mathrm{a}}$ & 26 & 28 \\
$\quad$ Stenosis symmetric & 20 & 199 & 219 \\
\cline { 2 - 4 } Total & 22 & 225 & 247 \\
\hline Study 2 & & & \\
$\quad$ Stenosis asymmetric & $2^{\mathrm{b}}$ & 24 & 26 \\
$\quad$ Stenosis symmetric & 9 & 218 & 227 \\
\cline { 2 - 4 } Total & 11 & 242 & 253 \\
\hline
\end{tabular}

${ }^{a}$ WML score higher distal to the stenosed side in both patients.

${ }^{\mathrm{b}}$ WML score higher distal to the stenosed side in one patient, and WML score lower distal to stenosis in the other patient.

in 3 , and distal to the non-stenosed side in 1). WML were asymmetric between hemispheres in $22(9 \%)$ and $11(4 \%)$ patients in Study 1 and Study 2, respectively; of these, across both studies, only 4 had asymmetric carotid stenosis (stenosis more severe proximal to the side with higher WML score in 3, and to the side with lower WML score in 1).
Combining both studies (1,000 carotid artery/hemisphere pairs), we found no association between carotid stenosis asymmetry and WML asymmetry (OR 1.15, 95\% CI 0.39-3.41). In the two studies combined, there was no association between WML and ipsilateral carotid stenosis, whether symptomatic or not (fig. 1). We also found no association between WML and ipsilateral carotid stenosis after adjusting for potential confounders, whether considering carotid stenosis as symptomatic versus asymptomatic ( $\mathrm{p}<0.001)$ or as left versus right ( $\mathrm{p}<0.001)$ (table 3). Only increasing age was associated with the overall WML score.

\section{Discussion}

In this study of two large cohorts of acute ischaemic stroke patients, we found no association between increasing carotid stenosis and increasing ipsilateral WML score, before or after adjusting for vascular risk factors. WML were strongly associated with increasing age $(\mathrm{p}<$ 0.001 ).

The main strengths of this study are the prospective collection of two cohorts of stroke patients who underwent brain MRI where we looked specifically at carotid stenosis and ipsilateral WML. Data collection was identical in each study using the same equipment and methods of imaging and quantifications. We included patients with a full range of carotid stenosis and WML, and applied several analyses, none of which demonstrated any association between carotid stenosis and WML.

The two neuroradiologists may have performed differently, introducing bias; however, both performed image reading to an internal standard, the studies had similar ranges of WML and our analysis initially examined the carotid stenosis/WML score within each study separately. We used visual WML scores rather than lesion volumes but, while volumes can give a more sensitive measure of WML, they may be distorted by accidental inclusion of infarcts that have similar signal to WML [16]. Although possibly less sensitive, visual WML scores are more specific as they do not suffer from this and related problems due to artifacts, and scores and volumes are closely related [17]. We made no adjustment for cardiac or aortic arch sources of the emboli, but this is unlikely to have had any significant influence on our results. The inclusion of some patients with either high-grade stenosis or carotid artery occlusion may have acted as a confounding factor due to the possibility of hypoperfusion-related WML [18], but if hypoperfusion were a mechanism, then 


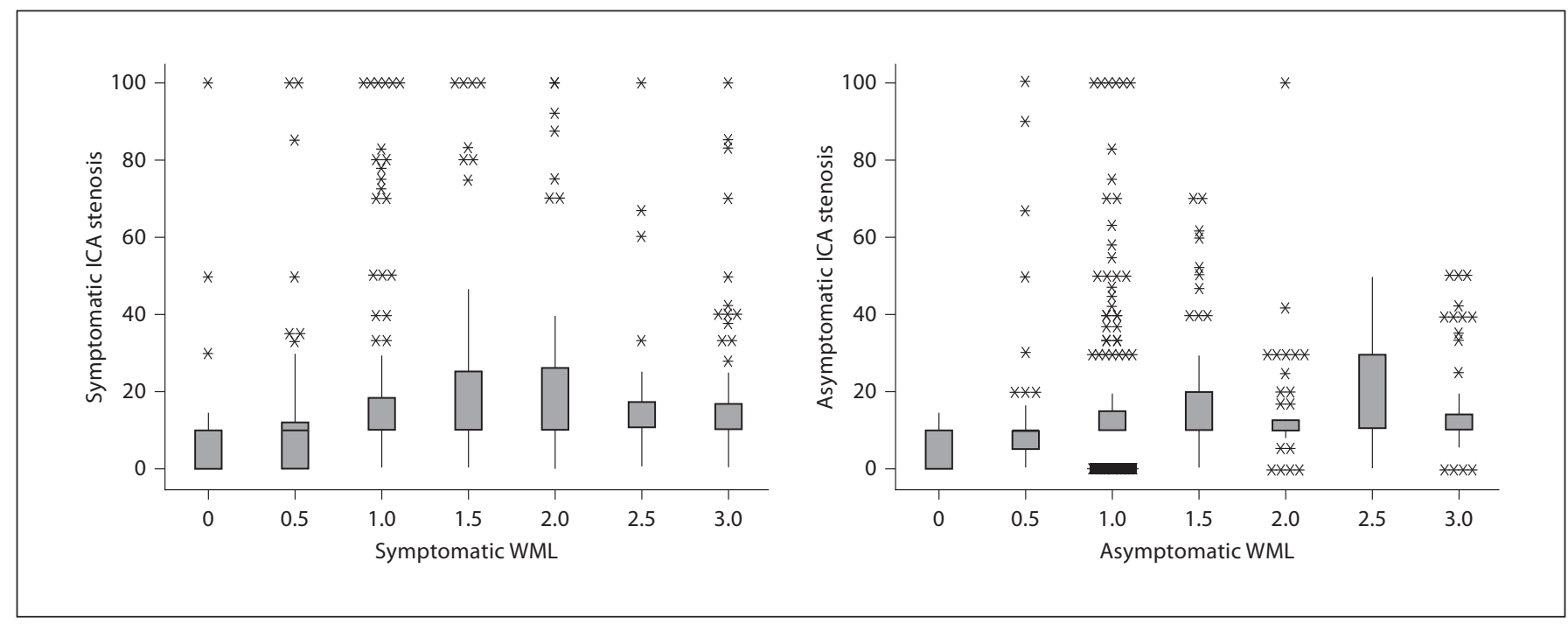

Fig. 1. Relationship between hemispheric WML scores (Fazekas) and ipsilateral carotid stenosis (\% NASCET) by symptomatic and asymptomatic sides, in both studies combined. WML scores were obtained by combining periventricular and deep WML scores and taking an average. Boxplots represent five-number summaries of NASCET stenosis (minimum, lower quartile, median, upper quartile and maximum values) with dots representing outliers. ICA = Internal carotid artery.

Table 3. Association between hemispheric WML and ipsilateral carotid artery stenosis adjusted for vascular risk factors

\begin{tabular}{|c|c|c|c|c|}
\hline & \multicolumn{2}{|c|}{ Symptomatic hemisphere WML } & \multicolumn{2}{|c|}{ Asymptomatic hemisphere WML } \\
\hline & OR $(95 \% \mathrm{CI})$ & $\mathrm{p}$ & OR $(95 \% \mathrm{CI})$ & $\mathrm{p}$ \\
\hline Increasing age & $1.10(1.07-1.12)$ & 0.00 & $1.10(1.08-1.12)$ & 0.00 \\
\hline Diabetes & $0.84(0.46-1.55)$ & 0.58 & $0.90(0.49-1.67)$ & 0.75 \\
\hline Hypertension & $1.18(0.78-1.79)$ & 0.44 & $1.15(0.76-1.75)$ & 0.50 \\
\hline Carotid stenosis (\%) & $1.0(1.0-1.01)$ & 0.44 & $0.99(0.98-1.00)$ & 0.24 \\
\hline
\end{tabular}

we should still have found an association between WML and increasing stenosis. As relatively few patients had asymmetric stenosis (11\% in Study 1 and 10\% in Study 2), we cannot fully exclude an association between WML and carotid stenosis, although the absence of any association between stenosis and ipsilateral WML when the two studies were combined effectively rules this out. Also, these frequencies of asymmetry for carotid stenosis are typical of stroke patients, and WML are generally symmetrical, as in the present study, so if an association between carotid stenosis and WML does exist, it is likely to be weak and indirect.

Carotid stenosis is associated with a high risk of ipsilateral cortical ischaemic stroke and transient ischaemic attack. Several studies suggest that carotid stenosis is infrequent in lacunar stroke such that it may be coincidental [19], despite which, emboli may still be regarded as an important cause of lacunar stroke and WML. Amongst 12 previous studies $(\mathrm{n}=7,843)$ assessing carotid stenosis versus WML score, $2(\mathrm{n}=2,118)$ found an association between increasing stenosis and increasing total brain (not ipsilateral) WML and $10(\mathrm{n}=5,725)$ did not (table 4) [18, 20-29]. The populations and research methods differed in these studies; only some adjusted for some risk factors or age, so it is possible that any association between stenosis and WML is actually due to co-association with a third factor, e.g. age or hypertension, which was not adjusted for. Only 3 studies assessed the relationship be- 


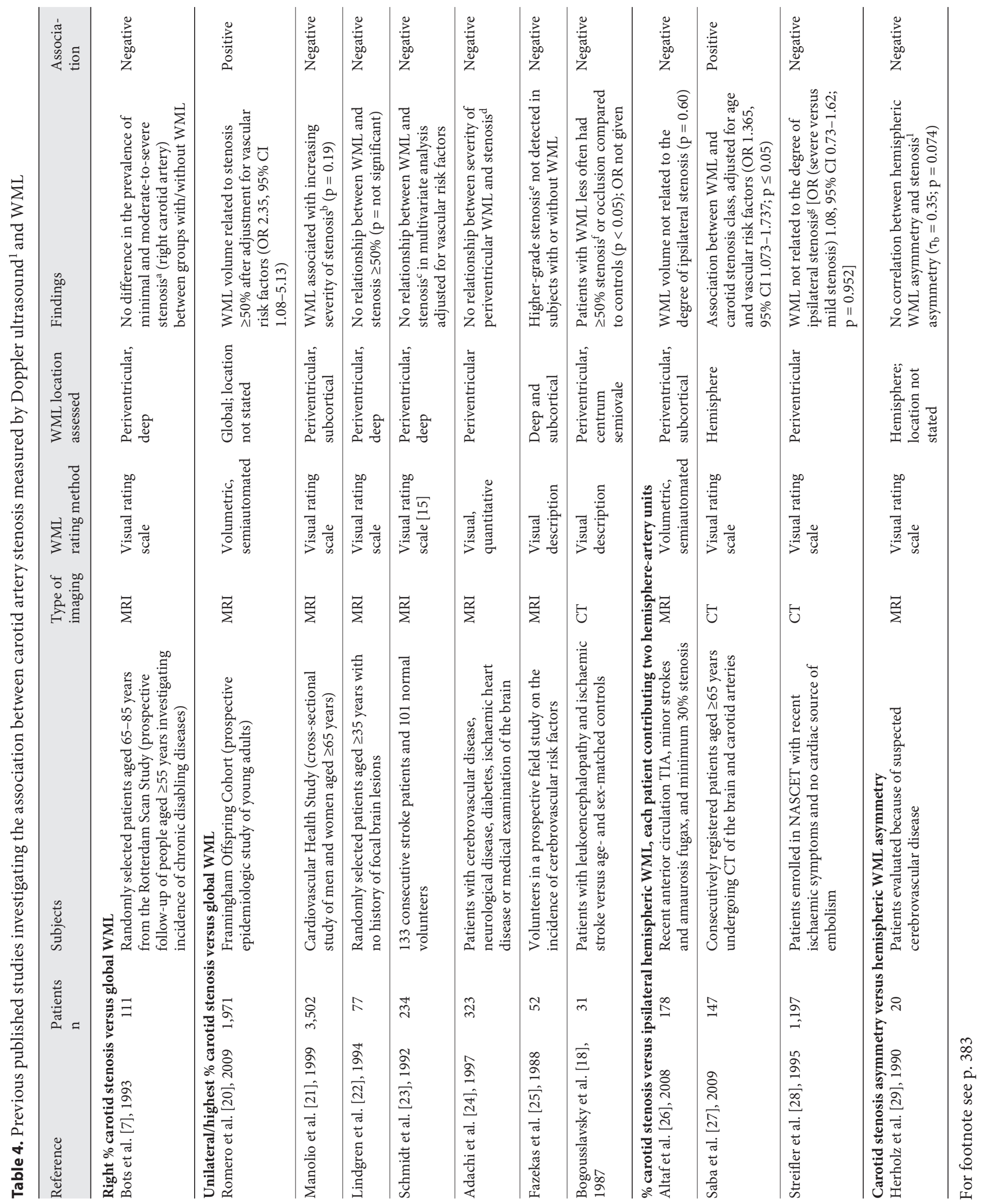


tween increasing carotid stenosis and ipsilateral WML $(\mathrm{n}=1,395)$ [26-28], but 2 used CT, which is less sensitive to WML than MRI $[27,28]$, and the third was small [26]. Our results are in agreement with those of Herholz et al. [29], who assessed asymmetric WML versus asymmetric carotid stenosis, but in only 20 patients. Our findings are also similar to those of Altaf et al. [26], although these authors did not consider carotid artery/hemispheres in relation to symptoms. There are now 11 studies, including ours, totaling 6,225 patients, which have not shown any association between WML and ipsilateral carotid stenosis, including 4 which examined individual artery/ hemisphere units; of these, ours is the only study to account for the opposite artery/hemisphere unit by considering left versus right, and symptomatic versus asymptomatic, sides. A recent study by Schulz et al. [30] (presented only in abstract form) showed WML were not associated with carotid stenosis, agreeing with our data that WML form independently of atherosclerotic disease; these authors also assessed WML asymmetry versus carotid stenosis asymmetry and found no association.

In conclusion, we found no association between increasing carotid stenosis and ipsilateral WML. Existing data provide substantial evidence that atherothromboemboli have little role in WML formation (or by association, with most lacunar ischaemic stroke), and that any suggestion of an association in previous studies between embolic sources and WML may simply have been due to a third co-associated mediating factor, such as age or hypertension. Future studies should focus on determining what causes the intrinsic small vessel pathological changes that appear to underlie most WML.

\section{Acknowledgements}

We would like to thank the patients and carers, and the doctors, administrators, radiographers, stroke clinical audit and programming staff who contributed to the collection of data. We are especially grateful for the clinical input from Professors Charles Warlow and Peter Sandercock, the neuroradiological input from Dr. Andrew Farrall, the programming assistance from Aidan Hutchison and Mike McDowall, and the administrative support from Kirsten Shuler and Isabel Jennings.

\section{Funding}

C.L.M.S., C.A.J. and the Study 1 stroke research register were funded by the Wellcome Trust (grant number 063668, Clinician Scientist Award to C.L.M.S.) and the Binks Trust. Study 2 was funded by the Chief Scientist Office of the Scottish Executive (grant number 217 NTU R37933) and the Wellcome Trust (grant number 075611). J.M.W. was funded by the Scottish Funding Council SINAPSE Initiative (Scottish Imaging Network, A Platform for Scientific Excellence, www.sinapse.ac.uk). G.M.P. was funded by the National Health Service Lothian Research and Development Office and the Chief Scientist Office of the Scottish Executive. F.N.D. was funded by the Wellcome Trust (grant number 075611). Imaging was performed in the Scottish Funding Council Brain Imaging Research Centre at the University of Edinburgh, and in the Neuroradiology Department, Western General Hospital, Edinburgh, UK.

\section{Disclosure Statement}

The authors have no conflicts of interest to disclose.

(Footnote to table 4)

\footnotetext{
${ }^{1}$ Except for Herholz et al. (stenosis measured by catheter angiography or Doppler ultrasound; stenosis graded $0=$ no stenosis; $1=<70 \%$ stenosis; $2=\geq 70 \%$ stenosis; $3=$ occlusion).

${ }^{\text {a }}$ Graded normal: minimal $=1-15 \%$ stenosis moderate $=16-$ $49 \%$ stenosis; severe $=\geq 50 \%$ stenosis.

b Graded as 0\%, 1-24\%, 25-49\%, 50-74\%, 75-99\% and $100 \%$ stenosis.

${ }^{\mathrm{c}}$ Graded 1-5: $0=$ no atherosclerotic lesion; $1=$ discrete atherosclerotic lesion at one side $(<20 \%) ; 2=20-50 \%$ stenosis at one side or discrete atherosclerotic lesions at both sides; $3=50-70 \%$ stenosis at one side or $20-50 \%$ stenosis at both sides; $4=>0 \%$ stenosis at one side, $50-70 \%$ stenosis at both sides, or occlusion at one side; $5=\geq 70 \%$ stenosis or occlusion at both sides.
}

${ }^{\mathrm{d}}$ Graded 1-5: 1 = no lesions; $2=<30 \%$ stenosis; $3=30-75 \%$ stenosis; $4=\geq 75 \%$ stenosis; $5=$ occlusion; grouped as: $1=$ unilateral grade 2 or lower; 2 = bilateral grade 2 or unilateral grade 3; 3 = bilateral grade 3 or unilateral grade $4 ; 4=$ bilateral grade 4 or above or unilateral grade 5 .

${ }^{\mathrm{e}}$ Graded 0-3: 0 = no lesion; $1=$ unilateral $<20 \%$ stenosis; $2=$ bilateral $<20 \%$ or unilateral $20-50 \%$ stenosis; $3=$ bilateral $20-50 \%$ or unilateral $\geq 50-70 \%$ stenosis.

${ }^{\mathrm{f}}$ Graded as: normal or $<50 \%$ stenosis; $50-74 \%$ stenosis; $75-$ 99\% stenosis; occluded.

g Graded as: mild $=<30 \%$ stenosis; moderate $=30-69 \%$ stenosis; severe $=70-99 \%$ stenosis; occluded.

TIA $=$ Transient ischemic attack; $\tau_{\mathrm{b}}=$ tau beta statistic. 


\section{References}

1 Hachinski VC, Potter P, Merskey H: Leukoaraiosis. Arch Neurol 1987;44:21-23.

-2 Schmidt R, Scheltens P, Erkinjuntti T, Pantoni L, Markus HS, Wallin A, Barkhof F, Fazekas F: White matter lesion progression: a surrogate endpoint for trials in cerebral small-vessel disease. Neurology 2004;63: 139-144.

-3 Ovbiagele B, Saver JL: Cerebral white matter hyperintensities on MRI: current concepts and therapeutic implications. Cerebrovasc Dis 2006;22:83-90.

-4 Liou LM, Chen CF, Guo YC, Cheng HL, Lee HL, Hsu JS, Lin RT, Lin HF: Cerebral white matter hyperintensities predict functional stroke outcome. Cerebrovasc Dis 2011;29: 22-27.

5 Pantoni L, Garcia JH: Pathogenesis of leukoaraiosis. A review. Stroke 1997;28:652-659.

-6 Jeerakathil T, Wolf PA, Beiser A, Massaro J, Seshadri S, D’Agostino RB, DeCarli C: Stroke risk profile predicts white matter hyperintensity volume: the Framingham Study. Stroke 2004;35:1857-1861.

-7 Bots ML, van Swieten JC, Breteler MMB, de Jong PTVM, van Gijn J, Hofman A, Grobbee DE: Cerebral white matter lesions and atherosclerosis in the Rotterdam Study. Lancet 1993;341:1232-1237.

8 Jackson CA, Hutchison A, Dennis MS, Wardlaw JM, Lewis SC, Sudlow CLM: Differences between ischemic stroke subtypes in vascular outcomes support a distinct lacunar ischemic stroke arteriopathy: a prospective, hospital-based study. Stroke 2009;40: 3679-3684.

9 Wardlaw JM, Doubal F, Armitage P, Chappell F, Carpenter T, Muñoz Maniega S, Farrall A, Sudlow C, Dennis M, Dhillon B: Lacunar stroke is associated with diffuse blood-brain barrier dysfunction. Ann Neurol 2009;65:194-202.

10 Bamford J, Sandercock P, Dennis M, Burn J, Warlow C: Classification and natural history of clinically identifiable subtypes of cerebral infarction. Lancet 1991;337:1521-1526.

-11 North American Symptomatic Carotid Endarterectomy Trial. Methods, patient characteristics, and progress. Stroke 1991;22:711720.

12 Zwiebel WJ, Pellerito J: Introduction to Vascular Ultrasonography, ed 2. Philadelphia, WB Saunders Company, 1986.
13 Wardlaw JM, Lewis S: Carotid stenosis measurement on colour Doppler ultrasound: agreement of ECST, NASCET and CCA methods applied to ultrasound with intraarterial angiographic stenosis measurements. Eur J Radiol 2005;56:205-211.

14 Lewis SC, Wardlaw JM: Which Doppler velocity is best for assessing suitability for carotid endarterectomy? Eur J Ultrasound 2002;15:9-20.

15 Fazekas F, Chawluk JB, Alavi A, Hurtig HI, Zimmerman RA: MR signal abnormalities at $1.5 \mathrm{~T}$ in Alzheimer's dementia and normal aging. AJR Am J Roentgenol 1987;149:351356.

16 Enzinger C, Ropele S, Gattringer T, Langkammer C, Schmidt R, Fazekas F: Highgrade internal carotid artery stenosis and chronic brain damage: a volumetric magnetic resonance imaging study. Cerebrovasc Dis 2010;30:540-546.

17 van Straaten ECW, Fazekas F, Rostrup E, Scheltens P, Schmidt R, Pantoni L, Inzitari D, Waldemar G, Erkinjuntti T, Mäntylä R, Wahlund LO, Barkhof F, LADIS Group: Impact of white matter hyperintensities scoring method on correlations with clinical data: the LADIS study. Stroke 2006;37:836-840.

$\checkmark 18$ Bogousslavsky J, Regli F, Uske A: Leukoencephalopathy in patients with ischemic stroke. Stroke 1987;18:896-899.

19 Mead GE, Lewis SC, Wardlaw JM, Dennis MS, Warlow CP: Severe ipsilateral carotid stenosis and middle cerebral artery disease in lacunar ischemic stroke: innocent bystanders? J Neurol 2002;249:266-271.

20 Romero JR, Beiser A, Seshadri S, Benjamin EJ, Polak JF, Vasan RS, Au R, DeCarli C, Wolf PA: Carotid artery atherosclerosis, MRI indices of brain ischemia, aging, and cognitive impairment: the Framingham study. Stroke 2009;40:1590-1596.

21 Manolio TA, Burke GL, O’Leary DH, Evans G, Beauchamp N, Knepper L, Ward B: Relationships of cerebral MRI findings to ultrasonographic carotid atherosclerosis in older adults: the Cardiovascular Health Study. CHS Collaborative Research Group. Arterioscler Thromb Vasc Biol 1999;19:356-365.
22 Lindgren A, Roijer A, Rudling O, Norvving B, Larsson EM, Eskilsson J, Wallin L, Olsson B, Johansson BB: Cerebral lesions on magnetic resonance imaging, heart disease, and vascular risk factors in subjects without stroke. A population-based study. Stroke 1994;25:929-934.

23 Schmidt R, Fazekas F, Kleinert G, Offenbacher H, Gindl K, Payer F, Freidl W, Niederkorn K, Lechner H: Magnetic resonance imaging signal hyperintensities in the deep and subcortical white matter. A comparative study between stroke patients and normal volunteers. Arch Neurol 1992;49:825-827.

24 Adachi T, Takagi M, Hoshino H, Inafuku T: Effect of extracranial carotid artery stenosis and other risk factors for stroke on periventricular hyperintensity. Stroke 1997;28: 2174-2179.

25 Fazekas F, Niederkorn K, Schmidt R, Offenbacher H, Horner S, Bertha G, Lechner H: White matter signal abnormalities in normal individuals: correlation with carotid ultrasonography, cerebral blood flow measurements, and cerebrovascular risk factors. Stroke 1988;19:1285-1288.

26 Altaf N, Morgan PS, Moody A, MacSweeney ST, Gladman JR, Auer D: Brain white matter hyperintensities are associated with carotid intraplaque hemorrhage. Radiology 2008; 248:202-209.

27 Saba L, Sanfilippo R, Pascalis L, Montisci R, Mallarini G: Carotid artery abnormalities and leukoaraiosis in elderly patients: evaluation with MDCT. AJR Am J Roentgenol 2009;192:W63-W70.

28 Streifler JY, Eliasziw M, Benavente OR, Hackinski VC, Fox AJ, Barnett HJ: Lack of relationship between leukoaraiosis and carotid artery disease. The North American Symptomatic Carotid Endarterectomy Trial. Arch Neurol 1995;52:21-24.

29 Herholz K, Heindel W, Rackl A, Neubauer I, Steinbrich W, Pietrzyk U, Erasmi-Korber H, Heiss WD: Regional cerebral blood flow in patients with leukoaraiosis and atherosclerotic carotid artery disease. Arch Neurol 1990;47:392-396.

30 Schulz U, Meagher T, Rothwell PM, Briley D, Gruter B, Chandratheva A: Leukoaraiosis is unrelated to carotid stenosis or risk factors for atherosclerosis. J Neurol Neurosurg Psych 2010;81:e18. 